\title{
APRENDIZAGEM DE GEOMETRIA ANALÍTICA: POSSÍVEIS PAPÉIS DOS VÍDEOS NESTE CENÁRIO
}

\author{
Maisa Lucia Cacita Milani, Dulcinéia Ester Pagani Gianotto
}

Universidade Estadual de Maringá - UEM, Programa de Pós-Graduação em Educação para a Ciência e a Matemática, Maringá - PR. E-mail: mayzamilani@gmail.com.

\section{RESUMO}

Este estudo apresenta e discute parte dos dados de uma pesquisa de doutorado a qual investiga os vídeos digitais em face da aprendizagem significativa da geometria. Os vídeos estão presentes e fazem parte do cotidiano dos alunos, os quais têm grande aceitação desta forma de apresentação de informação. O estudo teve como objetivo investigar possíveis papéis do vídeo digital no processo de ensino e aprendizagem de conceitos de geometria analítica. Para tanto, a Teoria Cognitiva da Aprendizagem Multimídia e a Teoria da Aprendizagem Significativa foram os principais aportes teóricos. De abordagem qualitativa e natureza interpretativa, a análise dos dados versou sobre uma produção de vídeo elaborada por um grupo de alunos do Ensino Médio. Concluímos que os vídeos exercem influências positivas na aprendizagem de geometria analítica, evocam conhecimentos prévios e criam um ambiente de convite à aprendizagem.

PALAVRAS-CHAVE: Teoria da Aprendizagem Multimídia, Aprendizagem Significativa, Vídeos Digitais, Geometria.

\section{LEARNING OF ANALYTICAL GEOMETRY: POSSIBLE FUNCTIONS FOR VIDEOS IN THIS SCENARIO}

\begin{abstract}
This study presents and discusses part of the data of a doctoral research that investigates digital videos viewing the significant learning of geometry. The videos are present and are part of the daily life of the students, who have great acceptance of this form of presentation of information. The purpose of this study was to investigate possible functions for digital videos in the teaching and learning process of analytic geometry concepts. For that, the Cognitive Theory of Multimedia Learning and the Theory of Significant Learning were the main theoretical contributions. From a qualitative and interpretative approach, the analysis of the data was based on a video production by a group of High School students. We concluded that the videos exert positive influences in the learning of analytical geometry; they evoke previous knowledge and create an environment of invitation to learning.
\end{abstract}

KEYWORDS: Multimedia Learning Theory, Significant Learning, Digital Videos, Geometry. 


\section{INTRODUÇÃO}

No contexto social, os vídeos digitais, usando imagens e palavras dinâmicas, estão cada vez mais presentes no cotidiano dos jovens. Eles acessam conteúdos de entretenimento, de política, curiosidades, entre outros. Além disso, em alguns casos, produzem seus próprios vídeos sobre temas do seu interesse e até mesmo seguem youtubers, pessoas que produzem vídeos com temas variados, sendo que os acessos chegam a milhões.

Para Moran (1995, p. 28, grifo do autor):

O vídeo parte do concreto, do visível, do imediato, do próximo, que toca todos os sentidos. Mexe com o corpo, com a pele - nos toca e "tocamos" os outros, que estão ao nosso alcance, através dos recortes visuais, do close, do som estéreo envolvente. Pelo vídeo sentimos, experienciamos sensorialmente o outro, o mundo, nós mesmos.

Um vídeo com imagens e palavras dinâmicas convida quem assiste às cenas a sorrir, chorar, agir, etc., ou seja, instiga a razão e a emoção, por exemplo. Os sentidos parecem que ganham amplitude e profundidade quanto à apresentação de conhecimento popular ou científico por este meio. Nesse aspecto, "[...] trazer o vídeo digital - forma com a qual a nova geração faz piada, se comunica, se diverte - para sala de aula é importante" (BORBA et al., 2014, p. 100).

Os vídeos digitais não foram desenvolvidos ou planejados para fins educacionais, porém, são utilizados no contexto escolar com várias finalidades, como por exemplo: ilustrar conteúdos, trechos de filmes para explicar acontecimentos históricos, experimentos físicos, etc.

Especificamente na Educação Matemática esses são apontados na atual fase das tecnologias digitais: "[...] uma nova fase surge quando inovações tecnológicas possibilitam a constituição de cenários qualitativamente diferenciados de investigação matemática" (BORBA et al., 2014, p. 37). Isso significa que a utilização das tecnologias proporciona um pensamento inédito, quando o aluno se desenvolve cognitivamente, ou seja, um novo conhecimento matemático é desenvolvido por meio da tecnologia.

A aprendizagem, para Mayer (2009), é efetivada quando ocorre a integração das informações apresentadas pelas imagens e palavras com aquelas que estão armazenadas na memória de longo prazo, ou seja, por meio do conhecimento prévio.

O conhecimento prévio é o fator que mais interfere na aprendizagem (AUSUBEL, 2003; (AUSUBEL; NOVAK; HANESIAN, 1980). Para Ausubel (2003), a aprendizagem ocorre mediante a interação entre as novas informações e aquelas que já estão consolidadas na estrutura cognitiva de cada sujeito.

Ausubel (2003) aponta condições para a ocorrência da aprendizagem significativa: material potencialmente significativo e que o aluno apresente predisposição para aprender (AUSUBEL, 2003; MOREIRA, 2011; 2014). O material de aprendizagem (livros, aulas, aplicativos, entre outros) é considerado potencialmente significativo se tiver "significado lógico (isto é, seja relacionável de maneira não-arbitrária e não-literal a uma estrutura cognitiva apropriada e relevante" (MOREIRA, 2011, p. 24-25). A alta do preço de alimentos, por exemplo, relaciona-se significativamente à mudança climática, o que, por sua vez, está relacionado ao custo de produção, ou seja, há um encadeamento de ideias coerentes. A coerência do material é importante para garantir que a estrutura desse material não seja confusa nem arbitrária. Também, é "[...] necessário que o conteúdo ideacional relevante esteja disponível na estrutura cognitiva de um determinado aluno" (AUSUBEL; NOVAK; HANESIAN, 1980, p. 34). Isso significa que é necessário que o aluno possua "[...] em sua estrutura cognitiva ideias-âncora relevantes com as quais esse material possa ser relacionado" (MOREIRA, 2011, p. 25). Os significados de ideias-âncora se referem aos chamados subsunçores.

"A segunda condição é talvez mais difícil de ser satisfeita do que a primeira: o aprendiz deve querer relacionar os novos conhecimentos, de forma não-arbitrária e não-literal, a seus 
conhecimentos prévios" (MOREIRA, 2011, p. 25). Essa condição não se refere exatamente ao gosto ou mesmo à motivação pelo conteúdo. $O$ aluno se predispõe a modificar, enriquecer, elaborar e atribuir significados ao novo conhecimento.

O novo conhecimento é processado (entendido) pela via da interpretação da linguagem escrita e oral, ou seja, pela visão e pela audição (MAYER, 2009). Por meio desses dois canais, caso o aluno não possua necessidades especiais, ocorre a seleção de palavras e imagens pela memória sensorial, a organização das palavras e imagens pela memória de trabalho e a integração desses dois modelos com os conhecimentos prévios, pela memória de longo prazo. Para Mayer (2009, p. 1, tradução nossa): "As pessoas aprendem mais com palavras e imagens do que com palavras isoladas", ou seja, as pessoas aprendem mais profundamente quando as ideias são expressas por palavras e imagens concomitantemente, mais do que exclusivamente por palavras. Esse é a premissa da Teoria Cognitiva da Aprendizagem Multimídia (TCAM) proposta por Richard E. Mayer, em que são apontados 12 princípios a serem considerados em uma instrução multimídia, ou seja, a partir de vídeos digitais. Os princípios são indicações e apontamentos quanto à coerência, à sinalização das principais informações, à segmentação de conteúdos complexos, à pré-formação de conceitos relacionados ao entendimento do todo, à organização espacial, à voz amigável, à imagem, entre outros.

Diante desse cenário, o objetivo deste estudo foi investigar possíveis papéis do vídeo digital no processo de ensino e aprendizagem de conceitos de geometria analítica.

\section{METODOLOGIA}

O estudo de natureza qualitativa foi submetido à apreciação do Comitê Permanente de Ética em Pesquisa com Seres Humanos (COPEP), que foi aprovado sob o no 65587417.1.0000.0104. A abordagem qualitativa se mostra eficaz, pois o objeto de estudo pode ser analisado considerando-se opiniões, atitudes e práticas (LANKSHEAR; KNOBEL, 2008). André (2000) aponta que as investigações de base qualitativa na área da educação têm se mostrado muito produtivas por privilegiarem o modo de pensar dos participantes da pesquisa.

Os sujeitos da pesquisa foram 34 alunos do Ensino Médio de uma escola do norte do Paraná, que participaram de um curso de 40 horas, no período do contraturno, sendo que a participação ocorreu de forma voluntária.

Os instrumentos usados na coleta e na análise de dados foram: mapas conceituais, questionários (com respostas semiestruturadas), materiais produzidos pelos alunos (atividades escritas e vídeos), entrevistas (questões abertas), relatório de campo do pesquisador, gravações de áudio e vídeo. A análise versou sobre esses instrumentos, produzidos por um grupo de alunos citados como A1, A2, A3, A4 e A5.

As sequências de aulas foram divididas em nove encontros de $4 \mathrm{~h} / \mathrm{a}$ (50 min. para cada hora aula), obtendo-se um total de 40 horas. Foram desenvolvidas várias atividades usando vídeos de geometria analítica, sendo que esses foram disponibilizados no site do portal Educacional do Estado do Paraná ${ }^{1}$ e somam 10,84\% dos vídeos de matemática. Os vídeos foram analisados sob a ótica da TCAM, segundo os doze princípios (MAYER, 2009). Para tanto, utilizamos uma escala para avaliação indicada pela Escala Likert, cuja finalidade foi apontar a contemplação de cada princípio em cada vídeo. Os vídeos que mais contemplaram os princípios foram utilizados nas atividades.

\footnotetext{
${ }^{1}$ Disponível em: < http://www.matematica.seed.pr.gov.br/modules/video/arquivoVideos.php>. Acesso em: 08 fev. 2017. 


\section{RESULTADOS}

Quanto ao perfil dos alunos: eles têm acesso às tecnologias digitais em casa tais como: computadores, internet, celulares, etc., sendo que buscam vídeos de matemática para: compreender melhor o conteúdo, estudar para as provas, se prepararem para o vestibular e aprofundar seus conhecimentos. Todos já produziram algum tipo de vídeo de entretenimento, mas, não com conteúdos escolares. Ainda, acessam diariamente ou semanalmente vídeos com conteúdos escolares.

O desafio proposto foi apresentado pelo vídeo Jardim de Números ${ }^{2}$, o qual contempla de forma satisfatória os 12 princípios da TCAM. Nesse vídeo são apresentadas cenas nas quais uma estagiária, Kátia, recebe uma ligação de um cliente que quer um projeto que reproduza a bandeira do Brasil em um terreno de quase $300 \mathrm{~m}^{2}$, com 14 metros de largura por 20 de comprimento. Porém, ela fica preocupada, pois sua chefe estava viajando. Após assistir ao vídeo até essas cenas, os alunos começaram a discussão e a resolução da situação.

Eles levantaram hipóteses de resolução e possíveis conceitos matemáticos necessários para a resolução. Após a discussão e a resolução e antes de os alunos elaborarem o vídeo, eles participaram de um curso de análise de vídeos sob a ótica da TCAM, pelo facebook, em um grupo fechado. Para o grupo, um vídeo é considerado ruim quando: apresenta imagem e som sem qualidade, má produção (audiovisual), professor sem argumentos, falta de conteúdo; é muito longo, entre outros. O vídeo é considerado bom quando: apresenta boa qualidade de imagem, iluminação, conteúdo organizado e com sequência lógica, entre outros.

Com a resolução e o curso finalizados os alunos desenvolveram o material da resolução em formato de vídeo, com total de 5 minutos. O grupo intitulado "O tal dos analíticos" iniciou as cenas dizendo (todos juntos): "calma Kátia, os analíticos vão te ajudar". E depois encerraram: "agora é sua vez Kátia" ( $A 1, A 2, A 3, A 4, A 5)$.

As figuras 1, 2 e 4 ilustram algumas cenas produzidas pelos alunos.

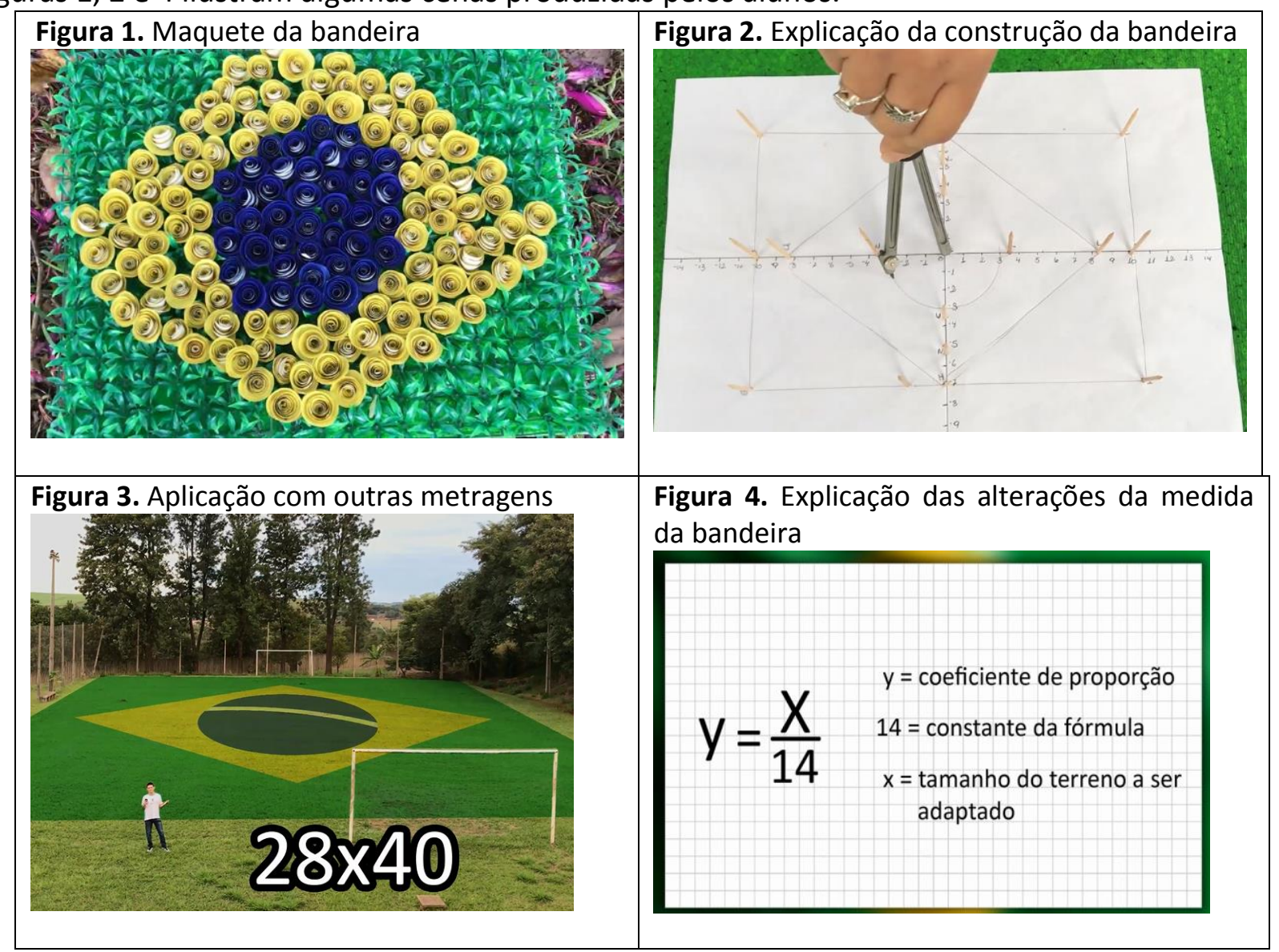

Fonte: Acervo das autoras.

${ }^{2}$ Disponível em: <https://www.youtube.com/watch?v=rPrWPs7gtEs>.

Colloquium Humanarum, vol. 14, n. Especial, Jul-Dez, 2017, p. 168-173. ISSN: 1809-8207. DOI: 10.5747/ch.2017.v14.nesp.000938 
Os alunos apontaram outras metragens de terrenos nos quais poderia ser construída a bandeira, sendo que para isso utilizaram os conceitos de razão e proporção. Esta foi uma hipótese levantada no início da atividade: " a gente vai ter que diminuir a bandeira para pôr no vídeo!"(A2)/ "Mas, não pode ficar deformada." (A3)/ "[...] a gente tem que aumentar ou diminuir usando a unidade de medidas, então como podemos fazer?"(A5)/ "Se aumentar a largura tem que aumentar a largura também?" (Professor)/ "Professora e se a gente fizesse por proporção?"(A2)/ "será que dá certo?" (professor). Após as indagações o grupo realizou os registros das discussões.

\section{DISCUSSÃO}

O conhecimento prévio dos alunos foi relevante na atividade, principalmente no levantamento de hipóteses e na elaboração dos vídeos, interferindo na resolução da atividade e na produção do material, visto que trouxeram conceitos matemáticos de proporção, fração, escalas, entre outros. Também, aplicaram os conhecimentos relacionados à produção do vídeo, como aqueles a respeito de utilização de software de edição, elaboração de roteiro, produção de material concreto para representar a situação problema, etc. Ao discutir e levantar as hipóteses, conteúdos matemáticos, tecnologias necessárias, entre outros, o grupo sempre teve a preocupação de conhecer cada um desses elementos. Isso é indicado em falas como: "eu não lembro bem de escala mais acho que dá sim para resolver"(A5). Para Ausubel (2003), "[...] é necessário que o conteúdo ideacional relevante esteja disponível na estrutura cognitiva de um determinado aluno" (AUSUBEL; NOVAK; HANESIAN, 1980, p. 34). Segundo Mayer (2009), a aprendizagem ocorre mediante a integração da nova informação (palavras e imagens) com o conhecimento prévio.

"A segunda condição é talvez mais difícil de ser satisfeita do que a primeira: o aprendiz deve querer relacionar os novos conhecimentos, de forma não-arbitrária e não-literal, a seus conhecimentos prévios" (MOREIRA, 2011, p. 25). O aluno deve querer, por algum motivo, transformar o significado lógico em psicológico, visto que o grupo aceitou o desafio proposto no vídeo, levantou hipóteses de resolução, discutiu, elaborou a resolução no papel e concluiu com uma produção de vídeo dinâmica com música, maquete, explicação do conteúdo pelos integrantes, entre outros, que durou vários encontros no período do contraturno e sem valor de avaliação.

Isso são indícios de intencionalidade de transformar, relacionar, modificar, refinar o seu conhecimento prévio por meio do desafio apresentado pelo vídeo, respondendo a esse pela produção de vídeo, colocando-se no papel de produtor e ator das cenas.

Para Mayer (2009), "[...] o material estudado pode ser o responsável pelo nível de motivação do aluno" (p. 81, tradução nossa).

\section{CONCLUSÃO}

A partir da análise dos dados foi possível identificar possíveis papéis dos vídeos nesta atividade:

Um deles é o convite à aprendizagem de geometria analítica, sendo um material potencializador para gerar ambientes que favoreçam ou mesmo despertem a predisposição positiva para aprender, ou seja, criando um terreno fértil para tal propósito.

Outro diz respeito à evocação de conhecimentos prévios por meio de palavras e imagens dinâmicas. Quando o grupo se propõe a construir as cenas e se tornar protagonista do vídeo ele evoca todos os conhecimentos necessários para dar um enredo, ou seja, uma solução para aquele desafio, sejam eles conhecimentos matemáticos, tecnológicos, de português, etc. Observamos que, quando os alunos não conseguiam dar sequência ou executar a cena, buscavam conceitos e ferramentas para completar as lacunas, tanto pela explicação do professor quanto em pesquisas 
na internet, porém sempre partindo do que já conheciam. Isso ocorreu em vários momentos, principalmente durante a montagem dos slides e das cenas do vídeo.

Os vídeos digitais de geometria analítica, que contemplaram de forma satisfatória os princípios da TCAM, se mostraram como um material potencializador da aprendizagem, o qual exerceu forte influência, pois vários conceitos e formas de construção das cenas apresentaram características dos vídeos assistidos e analisados em outras atividades, que antecederam a atividade da construção do vídeo, como por exemplo: o personagem ter explicado o conteúdo, conceitos de plano cartesiano, localização de pontos, entre outros. Porém, não são todos os vídeos que apresentam contribuições significativas para o processo de ensino e aprendizagem de matemática, pois apresentam conceitos de forma confusa, sem sequência lógica, palavras e sons que não remetem ao tema abordado, entre outros.

Isso posto, o professor, ao utilizar vídeos digitais (palavras e imagens dinâmicas) nas aulas de Matemática, deve analisar se esse material tem potencial para gerar ambientes que convidem os alunos à aprendizagem, além de lançar um olhar crítico a essa forma de apresentação de informação.

\section{REFERÊNCIAS}

ANDRÉ, M. E. D. A. de. A pesquisa sobre formação de professores no Brasil, 1990-1998. In: ENCONTRO NACIONAL DE DIDÁTICA E PRÁTICA DE ENSINO, 10., 2000, Rio de Janeiro. Anais... Rio de Janeiro, 2000.

AUSUBEL, D. P. Aquisição e retenção de conhecimentos: uma perspectiva cognitiva. Lisboa: Plátano, 2003.

AUSUBEL, D. P.; NOVAK, J. D.; HANESIAN, H. Psicologia educacional. Tradução: Eva Nick. 2. ed. Rio de Janeiro: Interamericana, 1980.

BORBA, M. de C. et al. Fases das tecnologias digitais em educação matemática: sala de aula e internet em movimento. Belo Horizonte: Autêntica, 2014.

LANKSHEAR, C.; KNOBEL, M. Pesquisa pedagógica: do projeto à implementação. Porto Alegre: Artmed, 2008.

MAYER, R. E. Multimedia learning. 2. ed. New York: Cambridge University Press, 2009, https://doi.org/10.1017/CBO9780511811678.

MORAN, J. O vídeo na sala de aula. Comunicação e Educação, v. 2, p. 27-35. São Paulo, 1995.

MOREIRA, M. A. Aprendizagem significativa: a teoria e textos complementares. São Paulo: Editora Livraria da Física, 2011.

MOREIRA, M. A.; MASINI, E. F. S. Aprendizagem significativa: a teoria de David Ausubel. São Paulo: Centauro, 2001. 